\title{
Making distribution of wheelchairs sustainable: A Wheels for the World program in North India, October 2015
}

\author{
Jubin Varghese ${ }^{a}$, Nicole Hughes ${ }^{b}$, Nathan Grills ${ }^{c}$, Mukesh Kumar ${ }^{d}$, Lawrence Singh ${ }^{e}$, \\ Raj Kumar ${ }^{f}$
}

a MA, Deputy Director of Community Health and Disability Program Manager, Emmanuel Hospital Association, India
${ }^{b}$ BA (physiotherapy), Nossal Institute for Global Health, Melbourne, Australia
${ }^{c}$ MBBS, MPH, DPhil, Nossal Institute of Global Health, University of Melbourne, Australia
${ }^{d}$ BA, B.TH, Project Officer, Herbertpur Christian Hospital, Emmanuel Hospital Association, India
${ }^{e}$ B.Sc, Project Coordinator, Agnes-Kunze Society
${ }^{f}$ MA, MSW, Project Manager, Landour Community Hospital, Emmanuel Hospital Association, India

The Wheels for the World program is a program of Joni and Friends (JAF) wherein they make wheelchairs available to different parts of the world, and a team of volunteers travel to assess, modify, and fit wheelchairs for people with disabilities. They do all this in the love of Jesus and demonstrate the same mind as Jesus through their presence and service. In October 2015, the first Wheels for the World Program in North India took place. This program went ahead, despite concerns expressed by local North Indian partner organisations who asked about the sustainability and appropriateness of a foreign group coming in, charitably providing wheelchairs, and then leaving. Concerns about wheelchair distributions has been well documented elsewhere. ${ }^{1}$ However, the North Indian partners decided to be intentional about assuring that this event was sustainable, improved local knowledge, and linked with existing programs before and after the event. In this report, we outline the aspects that ensured this was the case.

To ensure the smooth running, contextualization, and sustainability of the 2015 North India Wheelchair Distribution (WCD), the two main event partners, Community Health Global Network, Uttarakhand Chapter (CHGN-UkC), and the Engage Disability regional hub came together to plan and strategize. A working committee was formed with members of each organization, as well as international partners, and they were given the responsibility for the logistics of the event. Herbertpur Christian Hospital was chosen as the venue as it was near Dehradun, North India, central to access, and had the appropriate facilities.

The first action towards sustainability was ensuring the involvement of multiple local partners and health organizations from North India. This enabled the WCD to be contextualized and ensured an ongoing impact. Operation Equip India is the Indian partner of JAF, and they helped with logistic planning and provided orthotists, physiotherapists, occupational therapists, etc. to support the foreign team. The CHGN-UkC is a group of faith-based organizations involved with health programs throughout Uttarakhand and have been focusing their work on disability inclusive programs. CHGN-UkC led the local development of the WCD and linked their 50-member programs into the event for referrals, fundraising, and support. The final key partner was Engage Disability regional hub, a group formed following the Engage Disability conference in 2013 that focused on the Church being central. Practical steps that NGOs could take to help support the ministry of the Church alongside those affected by disabilities were suggested. The Engage Disability regional hub involvement en-

Nov 2015. Christian Journal for Global Health, 2(2):72-75. 
sured that local churches were incorporated in the program and provided assurance of long term local follow-up for participants of the WCD.

The Engage Disability regional hub has been training pastors in the different local areas on disability for the last few years, and involvement in the WCD was seen as a practical follow-up of the training. The WCD was seen as an additional step in a series of activities to sensitize and to help the church engage with the community of those affected by disabilities. Therefore, the organizers decided that the event would be conducted through the local churches and pastors. This was done by means of the following:

- Information dissemination in the churches to raise prayer support, funds, volunteers, and referrals.

- Training for pastors on identifying needs of people affected by disability and completing referral forms. Pastors are linked locally and well placed to identify people with disabilities in their villages.

- The forms were screened on submission and dates were set for local Herbertpur physiotherapists and occupational therapists to meet with the people and do an initial assessment of the individual, home situation, and appropriateness for wheelchairs/aids.

- Plans were made to transport people to Herbertpur for the WCD and back with their wheelchairs and other aids.

- Training was conducted for volunteers assisting with the WCD, including those who would be providing counseling.

In securing the involvement of Church leaders, the following key actions were found to be important:

Enlist: Key Church leaders were enlisted in planning and organizing for their particular regions.

Nov 2015. Christian Journal for Global Health, 2(2):72-75.
Envisage: They were then helped to see the vision of the event and the future directions through workshops and meetings.

Communicate: Regular communication was maintained through phone and church visits to keep the idea on the radar.

Act: Church leaders developed specific plans of action for various churches.

Consolidate: Process of consolidation has been taken up following the event.

The engagement with the CHGN-UkC members promoted sustainability in a number of ways. This engagement meant that local therapists and program staff who were present and assisting in wheelchair fitting already knew the recipients that had been referred. Because the WCD team was well informed about the recipients and advice provided for follow-up, further fittings and reviews could often be given directly to their local therapist. The presence of the local therapists also meant that the foreign team could work closely with the local therapists for the wheelchair fittings. Many of the local therapists commented that they learnt more about fitting wheelchairs and mobility aids than they had in their entire training secondary to the expertise and experience of the international therapists and their capacity-building approach. The therapists were also taught how to modify and maintain the wheelchairs and other mobility aids. Finally, the therapists also became part of a fellowship of therapists from various local programs and from overseas. These linkages helped ensure long term sustainability and local empowerment.

The outcomes can be summarized as:

- The Dehradun city churches were involved through prayer support and raising funds to cover the costs of transportation from the camp site to their homes and other local costs and referrals.

- Seventeen house churches and 30 church volunteers were involved in conducting 
surveys in their communities, supporting the submission of the application forms, arranging the transportation, and staying with those who had come for aids during their assessments. During the application submission process, a number of people learned for the first time about disability certificates given by the government and their uses.

- Local pastors identified 310 persons with disability who required aids, and local therapists conducted 310 initial assessments to evaluate individual needs prior to the detailed assessment during the WCD. Selection was based on need alone and no preference was given on basis of gender, caste, age, or faith.

- Overall, 210 wheelchairs, 46 crutches, 42 walkers, and 32 canes were distributed, and each person was counseled and connected with the local pastor. The pastors have been given the responsibility of following up with the families with whom they have developed relationships through the last three months of survey, assessments, and WCD. The local pastors are able to work with families to help improve access to health services, community support/engagement, and access to governmental supports.

- Eight local therapists were trained and developed links and relationships with each other and with expertise from America. Additionally, staff and volunteers from the local programs developed closer friendships with families and pastors which should facilitate closer cooperation between NGO and churches in the future.

Follow-up visits with pastors have revealed stories of improved relationships with the community due to their stepping alongside those often neglected and by people with disability experiencing "love in action." In one of the regions, the pastors and second line leaders of house churches have committed to further disability training, beginning in November. The city churches are moving them towards a joint action to promote disability inclusion before the end of the year.

In conclusion, although wheelchair distributions have been criticized for being charity, for disempowering local programs, for unsustainability and inappropriateness, we believe this model avoids these pitfalls. By means of working through and with local disability programs, engaging with recipients before and after the event, recruiting religious leaders and training local therapists, this approach is more empowering, builds community, and benefits individuals in a way that accounts for their life context.

\section{References}

1. Krizack M. International wheelchair standards organizing committee formed [Internet]. Disability World. 2007;27. Available from: http://www.disabilityworld.org/1201_06/wheelchairstandards.shtml

Competing Interests: None declared.

Correspondence: Jubin Varghese, Emmanuel Hospital Association, India. jubin@eha-health.org Nicole Hughes, Nossal Institute for Global Health and The University of Melbourne, Australia. nicolehughes4@gmail.com Nathan Grills, Nossal Institute for Global Health and The University of Melbourne, Australia.ngrills@unimelb.edu.au

Nov 2015. Christian Journal for Global Health, 2(2):72-75. 
Cite this article as: Varghese J, Hughes N, Grills N, Kumar M, Singh L, Kumar R. Making distribution of wheelchairs sustainable: A Wheels for the World program in North India, October 2015. Christian Journal for Global Health (Nov 2015), 2(2): 72-75.

(C) Varghese J, Hughes N, Grills N, Kumar M, Singh L, Rajkumar This is an open-access article distributed under the terms of the Creative Commons Attribution License, which permits unrestricted use, distribution, and reproduction in any medium, provided the original author and source are properly cited. To view a copy of the license, visit http://creativecommons.org/licenses/by/3.0/

www.cjgh.org

Nov 2015. Christian Journal for Global Health, 2(2):72-75. 